\title{
MFG-E8 decreases intimal proliferation in a murine model of transplant vasculopathy
}

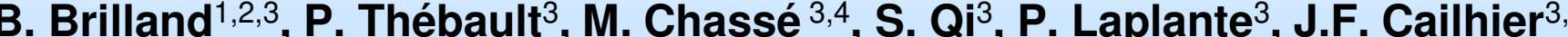

${ }^{1}$ Nephrology-Dialysis-Transplantation, Angers University Hospital and ${ }^{2}$ LUNAM University, Angers, France ; ${ }^{3} \mathrm{CHUM}$ Research Centre, ${ }^{4}$ ntesive Care Unit and ${ }^{5} \mathrm{Nephrology}$ Unit, Montreal University Hospital, Montreal, Quebec, Canada

\section{Introduction}

Milk Fat Globule Epidermal growth factor-8 (MFG-E8), released by apoptotic cells, can reprogram macrophages from a pro- to anti-inflammatory phenotype ${ }^{1}$. We aimed to study its role in a model of chronic transplant vasculopathy, the major cause of long-term allograft dysfunction in renal and heart transplantation ${ }^{2}$.

\section{Hypothesis}

Intragraft MFG-E8 is crucial to dampen local and systemic inflammation.

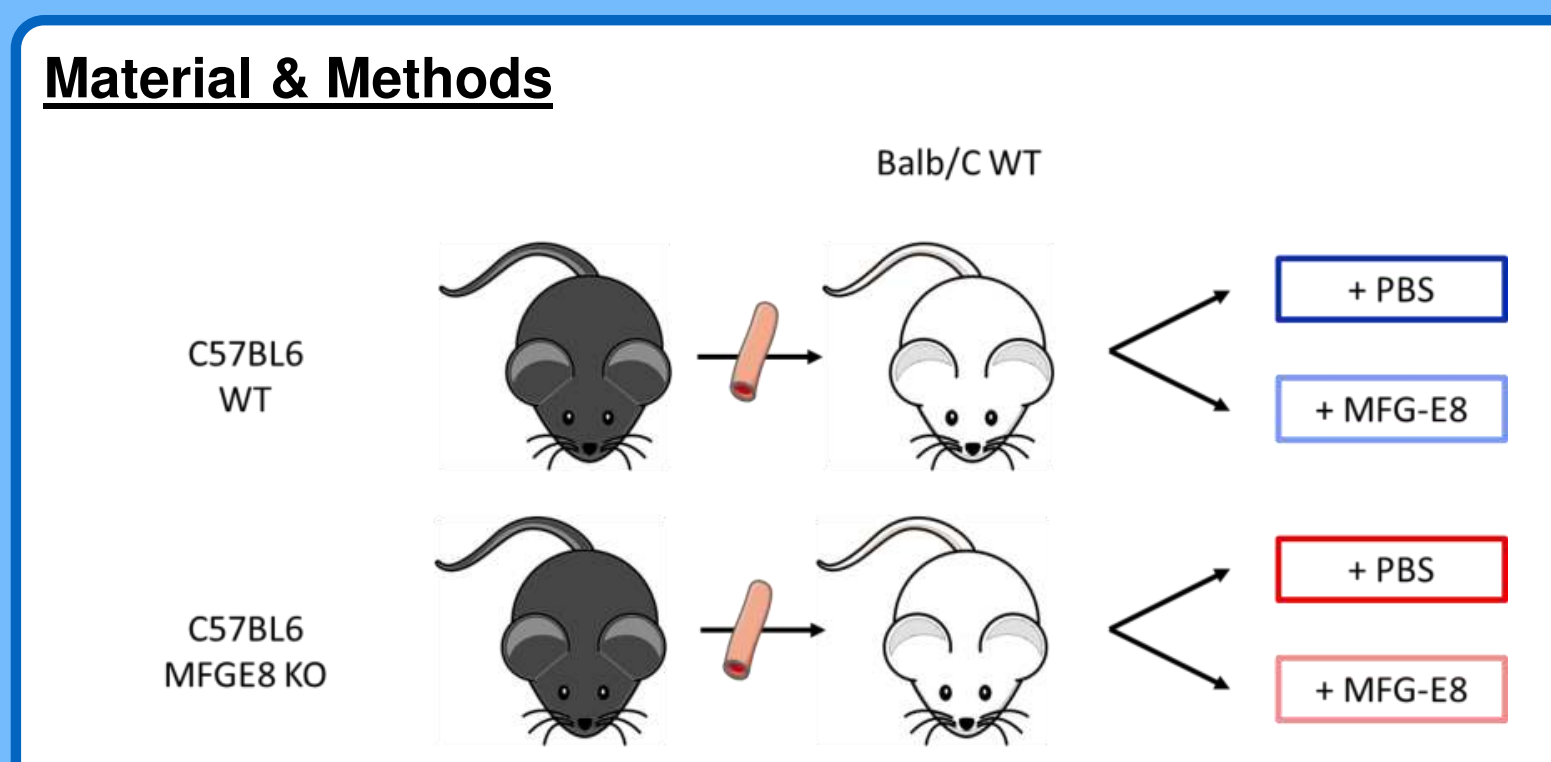

Figure 1 - Aortic transplantation and MFG-E8 injection procedures $(30 \mu \mathrm{g} / \mathrm{kg}$, intraperitoneally, twice a week). Isograft served as control (Balb/C aorta in Balb/C). $n=8-10$ per group.

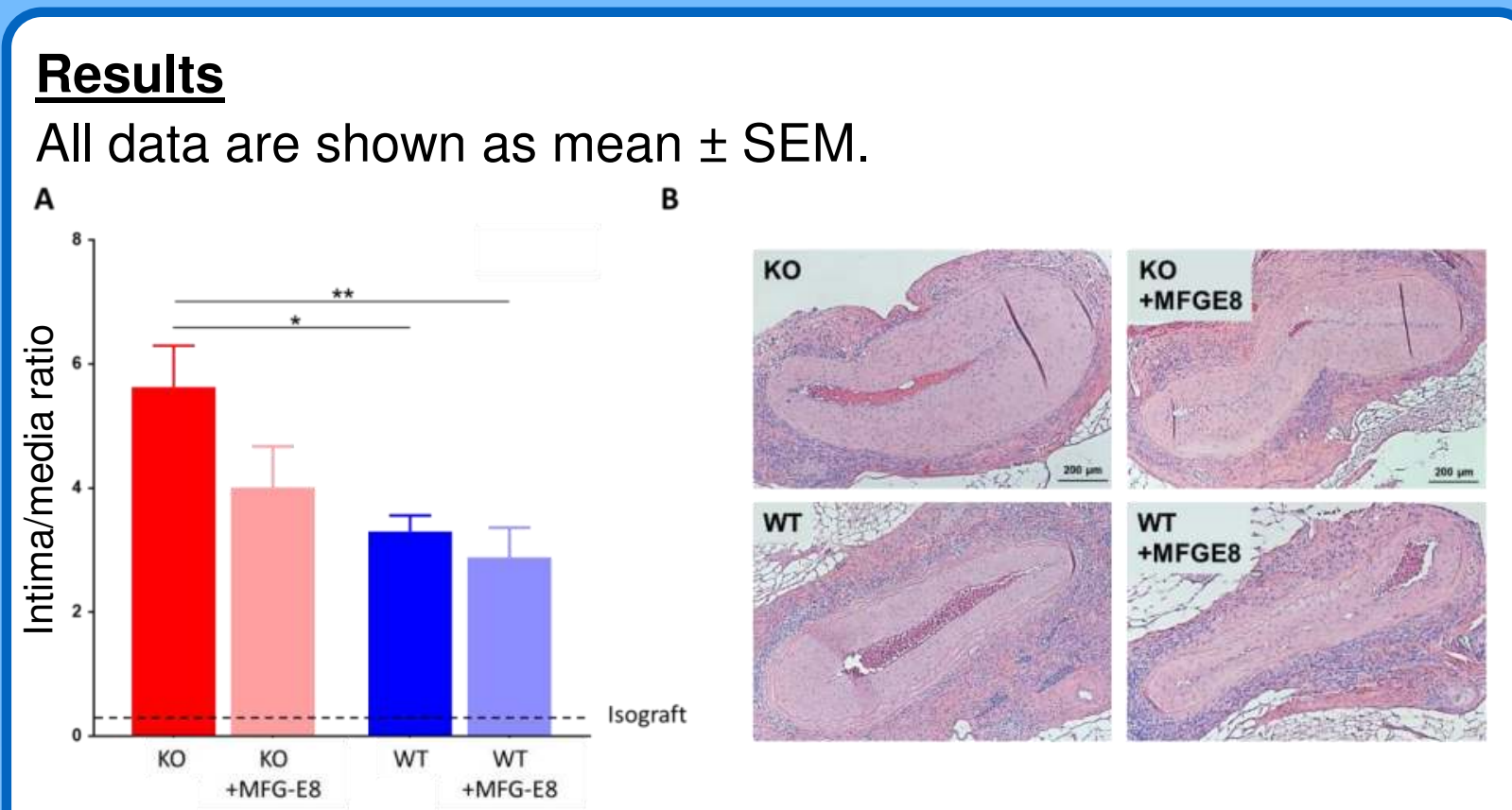

Figure 2 - MFG-E8 decreased intimal proliferation (intima/media ratio) of the allograft, evaluated at week 9 by Hematoxylin \& Eosin stain $\left({ }^{*} p<0,05 ;{ }^{* *} p<0,01\right.$; ANOVA + Tukey post-test). No rejection occurred in isograft group (intima/media ratio $=0.18$, doted line) .

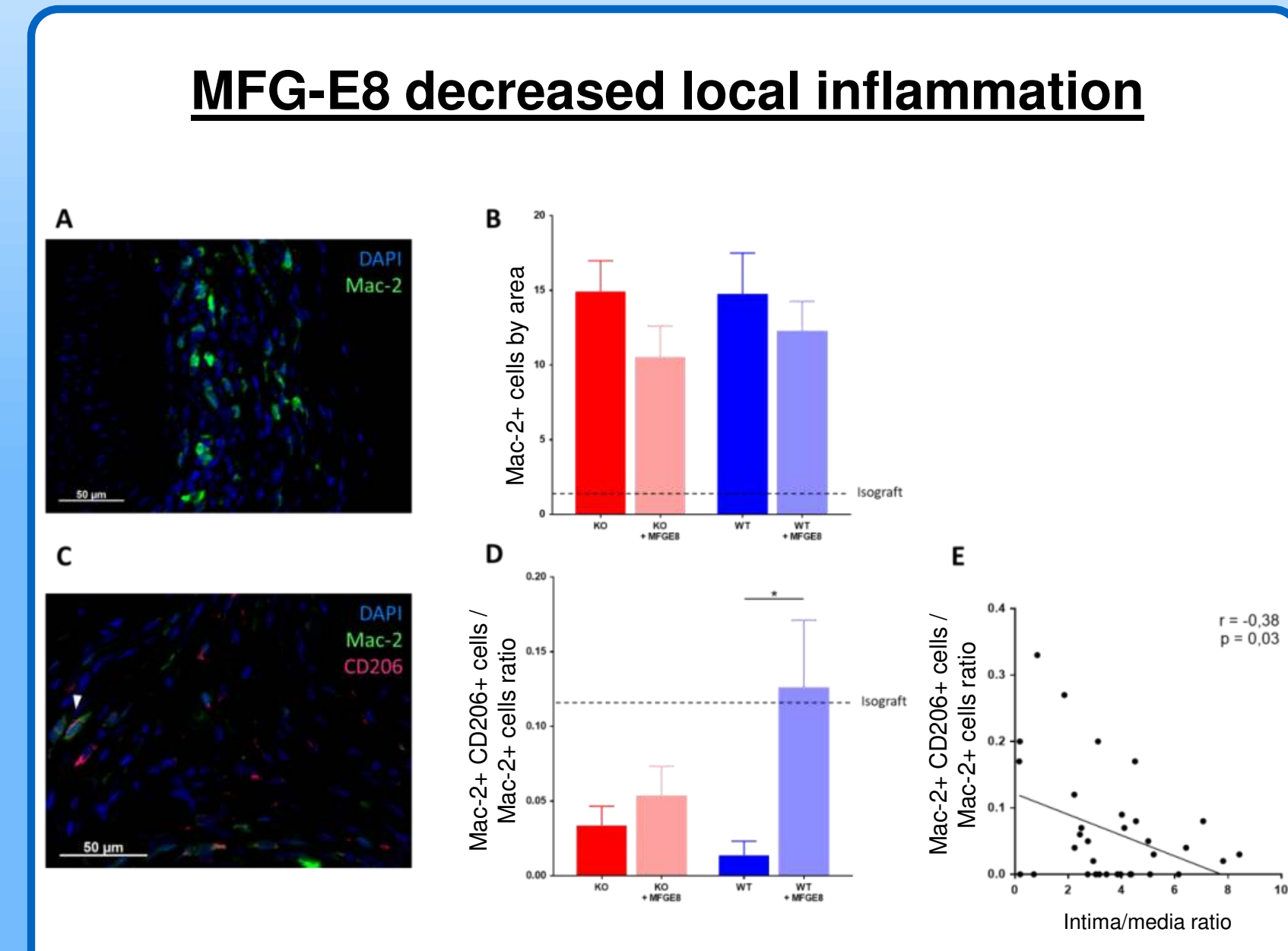

Figure 3 - (A) Macrophage infiltration (Mac-2+ cells) of the allograft, by immunofluorescence, at week 9 , seemed to decrease with MFG-E8 injection (B). (C) Anti-inflammatory macrophages (Mac-2+ CD206+ cells, arrow head). Proportion of anti-inflammatory macrophage infiltration increased with MFG-E8 (D) and negatively correlated with rejection (E) (Pearson test).
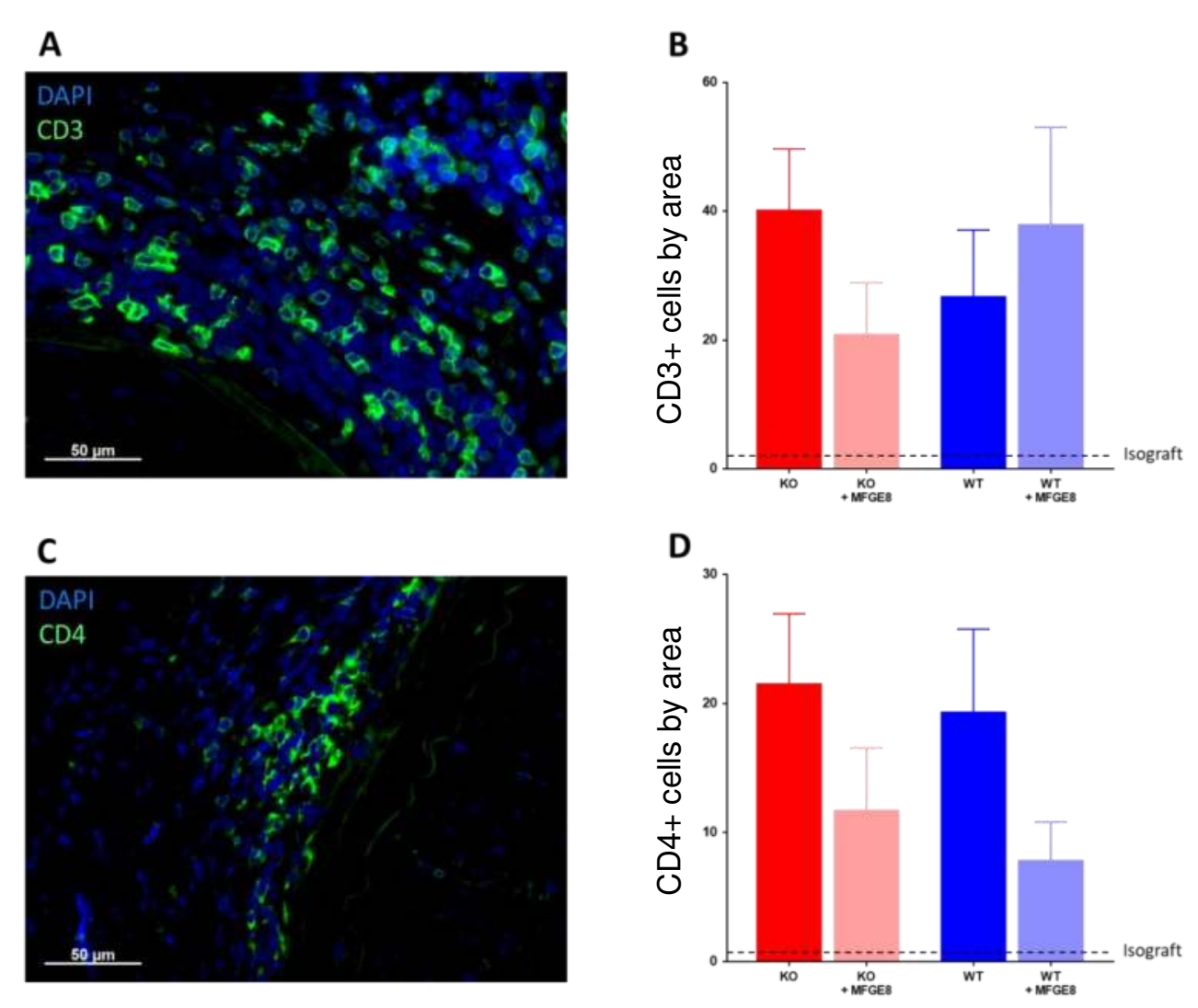

Figure $4-(A-B) \underline{T}$ cell infiltration $(C D 3+$ cells) of the allograft, by immunofluorescence, at week 9 , was not modified by MFGE8. (C-D) CD4+ T cells (C) infiltration seemed to decrease with MFG-E8 injection.

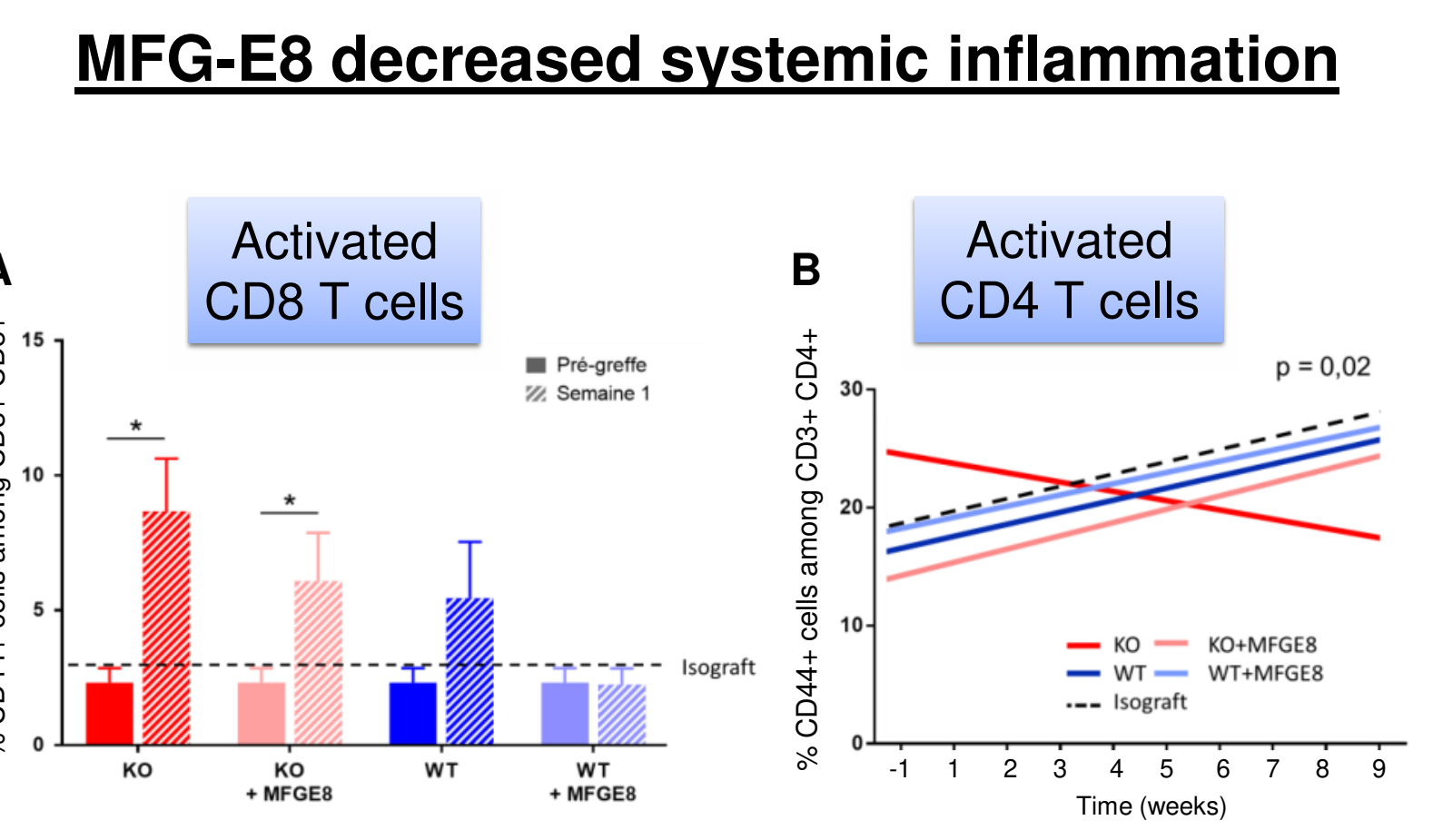

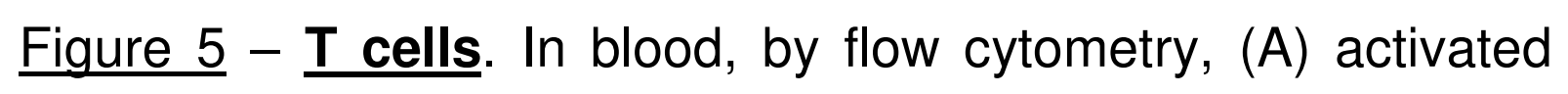
$\mathrm{CD} 8+\mathrm{T}$ cells at week 1 vs. before graft was higher in $\mathrm{KO}$ groups. $T$ test, ${ }^{*}: \mathrm{p}<0.05$. (B) Activated CD4+ $T$ cells overtime, using linear mixed model, was modulated by MFG-E8.
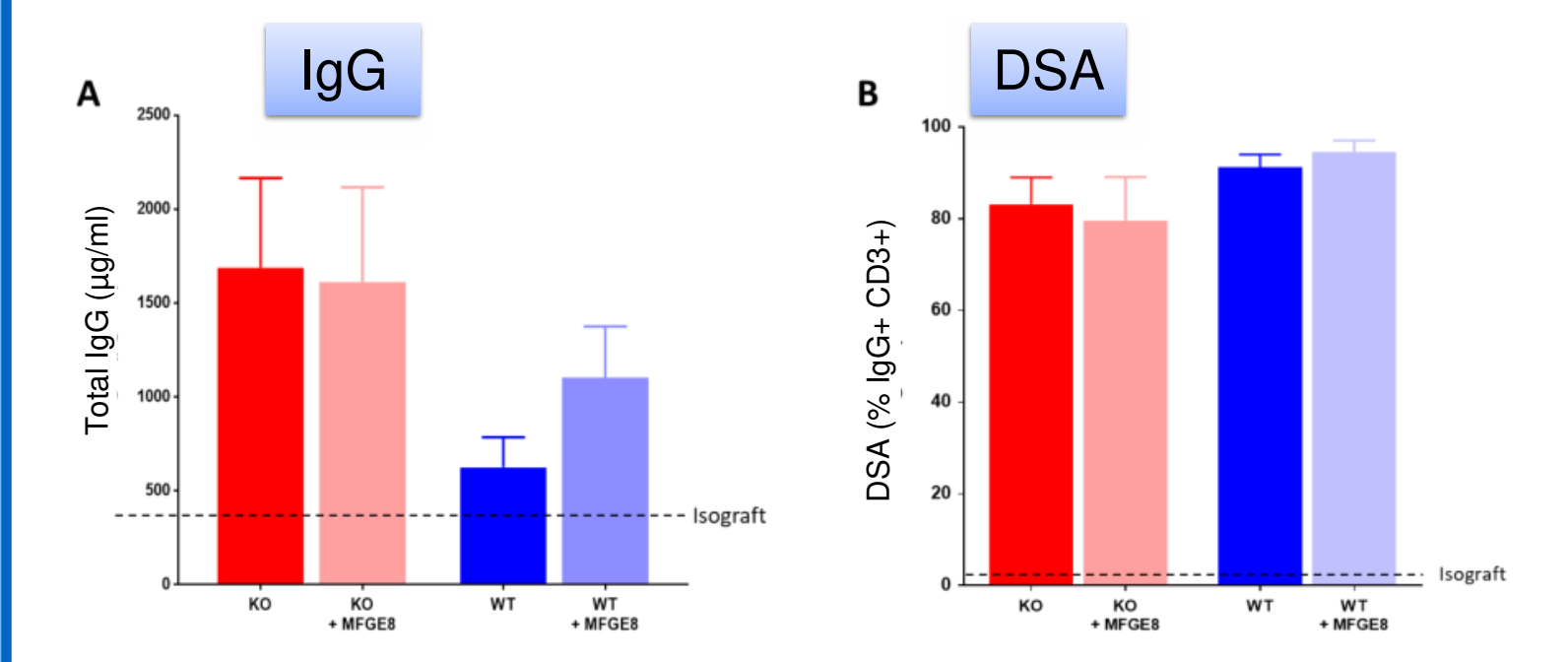

Figure 6 - B cells. (A) Total immunoglobulin $G(\lg G)$ levels, by ELISA, seemed to decrease in WT groups. (B) No difference in Donor Specific Antibodies (DSA) by flow cytometry.

\section{Conclusion}

Absence of MFG-E8 promotes increased intimal proliferation in the transplant. MFG-E8 decreases macrophage infiltration and increases anti-inflammatory macrophage infiltration. MFG-E8 also modulates activation of T cells. Thus, MFG-E8 improves transplant outcome by acting as an "analarmine" 3 , reducing the pro-inflammatory allograft microenvironment.

\section{References}

${ }^{1}$ Brissette et al., Plos One, 2012. ${ }^{2}$ Cailhier et al., Am J Transplant, 2006. ${ }^{3}$ Laplante et al., J Invest Dermatol, 2017 